\title{
Effect of Gamma Irradiation on Cement Composites Observed with XRD and SEM Methods in the Range of Radiation Dose 0-1409 MGy
}

\author{
A. ŁowińsKA-KLUGE ${ }^{a, *}$ AND P. PISZORA ${ }^{b}$ \\ ${ }^{a}$ Institute of Structural Engineering, Poznań University of Technology \\ Piotrowo 5, PL-60-965 Poznań, Poland \\ ${ }^{b}$ Department of Materials Chemistry, Faculty of Chemistry \\ Adam Mickiewicz University, Grunwaldzka 6, PL-60-780 Poznań, Poland \\ The effect of gamma radiation in the range of 0-1409 MGy on the struc- \\ ture of a new mineral additive to cement based composites was investigated \\ in the perspective of employing them as radioactive waste protection mate- \\ rial. According to the authors knowledge, it is the first paper dealing with \\ observations of the cement matrix, both pure and modified, treated with \\ so giant radiation dose. The absorption of gamma radiation modifies the \\ morphology of the additive grains, causes decomposition of cement hydrates \\ and clinker relicts in cement paste containing the additive at twice higher \\ radiation dose than that inducing the decomposition of the reference pure \\ cement paste and the cement paste containing pozzolane additives.
}

PACS numbers: 28.41.Kw, 28.41.Qb, 61.05.cp, 61.43.Er, 61.80.Ed, 68.37.Hk

\section{Introduction}

Safe storage of radioactive wastes is of essential importance for life and health on the Earth [1]. At present, the basic storage material is concrete based on pure cement as well as on cement modified with various mineral additives (e.g. fly ash and silica fume). Cement is commonly applied for manufacturing of containers and concrete shields, for sealing the bore-holes, shafts and tunnels in radioactive cemeteries located in rocky massifs. Cement is also used as a matrix enabling homogeneous distribution of radioactive components. Properties of the cement and additives determine the resistance of the protective material. Unfortunately, the

*corresponding author; e-mail: Lowinska-Kluge@wp.pl 
cement-based materials undergo radiation damage. Many research projects are aimed for improving the durability of cement based composites by their modification $[2-4]$.

Changes in the cement paste phase composition through a modification by mineral additives ${ }^{\dagger}$ decreases the contribution of the fraction of crystalline phases, e.g. portlandite $(\mathrm{C}-\mathrm{H})$, increases that of the fraction of gel phases, e.g. tobermorite-like phases $(\mathrm{C}-\mathrm{S}-\mathrm{H})$, and reduces the number of large capillary pores [5-7]. Gel phases extend the diffusion distance and hinder the penetration of aggressive chemical compounds. The modifications of this type enhance the resistance to aggressive agents and are usually realized by introduction of fly ash ${ }^{\ddagger}$ (FA) and/or silica fume ${ }^{\S}$ (SF), see Fig. 1a [8].

(a) CEMENTMATRIX

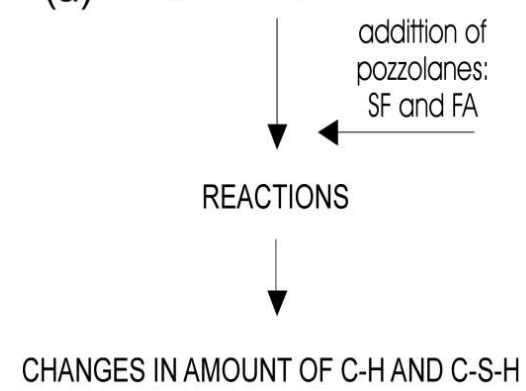

(b) CEMENT MATRIX

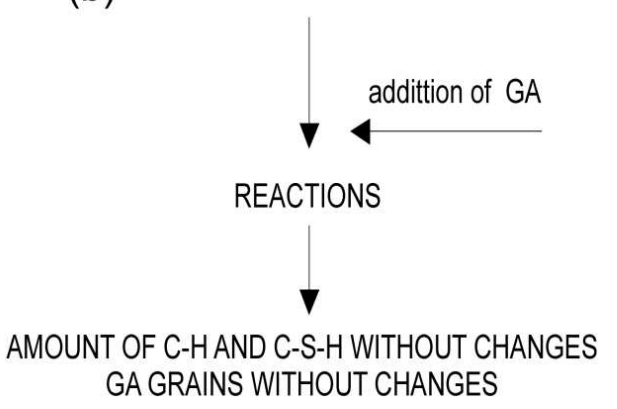

Fig. 1. The action scheme of additives in the cement pastes (up to 90 days) in normal conditions: (a) pozzolanes SF and FA; (b) GA.

Application of specific additives could enable cement matrix modification by radiation absorption in order to improve the durability of a cement-based composite. Activated GA granulate, which is an amorphous mineral obtained from industrial waste [9], can play such a role in the cement based composite (Fig. 1b). This additive transforms to crystalline phases under the influence of high temperatures. The GA additive gelates in acidic environments. As pH decreases, GA slowly activates and transforms into ionic form and modification of cement matrix by GA increases its chemical resistance to aggressive environments [10-12].

\section{Experimental details}

Granulates containing the GA and the GA-modified cement paste were exposed to gamma radiation along with some reference additives, as well as pure

\footnotetext{
${ }^{\dagger}$ European standard EN 206-1 "Concrete - Part 1: Specification, performance, production and conformity" defines concrete additives.

${ }^{\ddagger}$ European standard EN 450 "Fly ash for concrete - Definition, requirements and quality control".

${ }^{\S}$ European standard EN 13263 "Silica fume for concrete — Definition, requirements and conformity control.
} 
cement paste and cement pastes containing silica fume or fly ash. For more sample details see Table I. Cement pastes were placed in the radiation chamber after 90 days of hardening (involving mainly cement hydration processes and pozzolane reactions) $[5,6]$.

TABLE I

Examined samples and criteria of resistance to gamma radiation.

\begin{tabular}{|c|c|c|}
\hline Sample & Sample label & Criteria of durability \\
\hline \multicolumn{2}{|l|}{ Pure additives } & \multirow{4}{*}{$\begin{array}{l}\text { Phase transformations in tested } \\
\text { samples: } \\
\text { surface - comparison of objects } \\
\text { observed in SEM; } \\
\text { bulk - comparison of XRD } \\
\text { patterns }\end{array}$} \\
\hline $\begin{array}{l}\text { activated granulate, amorphous } \\
\text { mineral additive obtained from } \\
\text { industrial waste }\end{array}$ & GA & \\
\hline silica fume & $\mathrm{SF}$ & \\
\hline fly ash & FA & \\
\hline \multicolumn{2}{|l|}{ Pastes, after 90 days: } & \multirow{5}{*}{$\begin{array}{l}\text { Phase transformations in tested } \\
\text { samples:* } \\
\text { surface - comparison of objects } \\
\text { observed in SEM; } \\
\text { bulk - comparison of XRD } \\
\text { patterns }\end{array}$} \\
\hline pure cement paste & $\mathrm{PO}_{\mathrm{OPC}}$ & \\
\hline GA-modified cement paste & PGA30 & \\
\hline cement paste containing fly ash & PFA60 & \\
\hline $\begin{array}{l}\text { cement paste containing silica } \\
\text { fume }\end{array}$ & PSF10 & \\
\hline
\end{tabular}

Gamma ${ }^{60} \mathrm{Co}$ radiation in a radiation chamber with general activity of $1036 \mathrm{TBq}$ and the dose power of $38-40 \mathrm{kGy} / \mathrm{h}$ were applied. Temperature in the chamber was stabilized at $20 \pm 2^{\circ} \mathrm{C}$. Structural transformations were systematically verified for 10 years. Samples exposed to different doses of gamma radiation were tested using scanning electron microscopy (SEM) and X-ray diffraction (XRD) (c.f. Table II and III). Phase composition was determined using Co $K_{\alpha}$ radiation on computer-aided TUR-61 X-ray diffractometer equipped with HZG-3 goniometer. X-ray data were collected using Xdata [13] software (ver. 8255-HZG-3), X-ray spectra were processed using Xview [14] software (ver. 2.01). Measurements were performed in the $10^{\circ}-80^{\circ} 2 \Theta$, range, with the $0.02^{\circ}$ detector step and $5 \mathrm{~s}$ counting time. Phase analyses were performed using Xrayan [15] and Powder Cell 2.3 [16] programs. Peaks were labelled using abbreviations commonly accepted in cement chemistry (c.f. phase names and their abbreviations: quartz $(\mathrm{Q})$; portlandite $(\mathrm{P})$; calcite $(\mathrm{K})$; ettringite $(\mathrm{E})$; belite $(\mathrm{B})$; alite $(\mathrm{A})$; gypsum $(\mathrm{G})$; tobermorite $(\mathrm{T})$; va- 
terite $(\mathrm{V})$; brownmillerite $(\mathrm{Bm})$; monosulfate $(\mathrm{M})$; mullite $(\mathrm{Mu})$; syllimanite $(\mathrm{St})$; $\left.\mathrm{Ca}(\mathrm{OH})_{2}(\mathrm{C}-\mathrm{H}) ; n \mathrm{CaO} \cdot p \mathrm{SiO}_{2} \cdot q \mathrm{H}_{2} \mathrm{O}(\mathrm{C}-\mathrm{S}-\mathrm{H})\right)$.

TABLE II

Irradiated samples, applied doses, and observed effects for additives.

\begin{tabular}{c|c|c|c|c|c|c|l}
\hline \hline & \multicolumn{5}{|c|}{ Radiation dose [MGy] } & \multicolumn{1}{c}{ Observation } \\
\hline & 0 (ref.) & 350 & 466 & 520 & 685 & 1409 & \\
\hline GA & $+/-$ & $+/+$ & $+/+$ & $+/+$ & $+/+$ & $+/+$ & $\begin{array}{l}\text { progressive surface crystal- } \\
\text { lization, sample amorphiza- } \\
\text { tion in bulk }\end{array}$ \\
\hline SF & $+/-$ & $+/-$ & $+/-$ & $+/-$ & $+/-$ & $+/-$ & without changes \\
\hline FA & $+/-$ & $+/-$ & $+/-$ & $+/-$ & $+/-$ & $+/-$ & without changes \\
\hline
\end{tabular}

$+/+$ investigated/sample changes; $+/-$ investigated/without visible changes

TABLE III

Irradiated samples, applied doses, and observed effects for pastes.

\begin{tabular}{l|c|c|c|c|c|c|c|l}
\hline \hline & \multicolumn{7}{|c|}{ Radiation dose [MGy] } & Observation \\
\hline & 0 ref. & 68 & 130 & 290 & 466 & 836 & 1188 & \\
\hline POOPC & $+/-$ & $+/+$ & $+/+$ & $+/+$ & $+/+$ & $+/+$ & decomposition & \\
\hline PGA30 & $+/-$ & $+/+$ & $+/+$ & $+/+$ & $+/+$ & $+/+$ & $+/+$ & $\begin{array}{l}\text { progressive } \\
\text { decomposition }\end{array}$ \\
\hline PSF10 & $+/-$ & $+/+$ & $+/+$ & $+/+$ & $+/+$ & $+/+$ & $+/+$ & $\begin{array}{l}\text { progressive } \\
\text { decomposition }\end{array}$ \\
\hline PFA60 & $+/-$ & $+/+$ & $+/+$ & $+/+$ & $+/+$ & $+/+$ & $+/+$ & $\begin{array}{l}\text { progressive } \\
\text { decomposition }\end{array}$ \\
\hline
\end{tabular}

$+/+$ investigated/sample changes; +/- investigated/without visible changes

Surface morphology was observed using the variable pressure VEGA TS 5135 MM scanning electron microscope (SEM).

\section{Results and discussion}

Surface effects observed on irradiated grains of GA additive in SEM (Fig. 2) indicate subsequent structural transformations. The phenomenon is proposed to be attributed to a conversion of the gamma radiation energy to the crystal lattice energy. Other additives (FA, SF) did not reveal such effects.

Figure 3 presents the results of XRD for GA irradiated with different doses. At the highest dose $(\approx 1400$ MGy, Fig. $3(4))$ the broad peaks, ascribed to GA before irradiation, disappeared. 


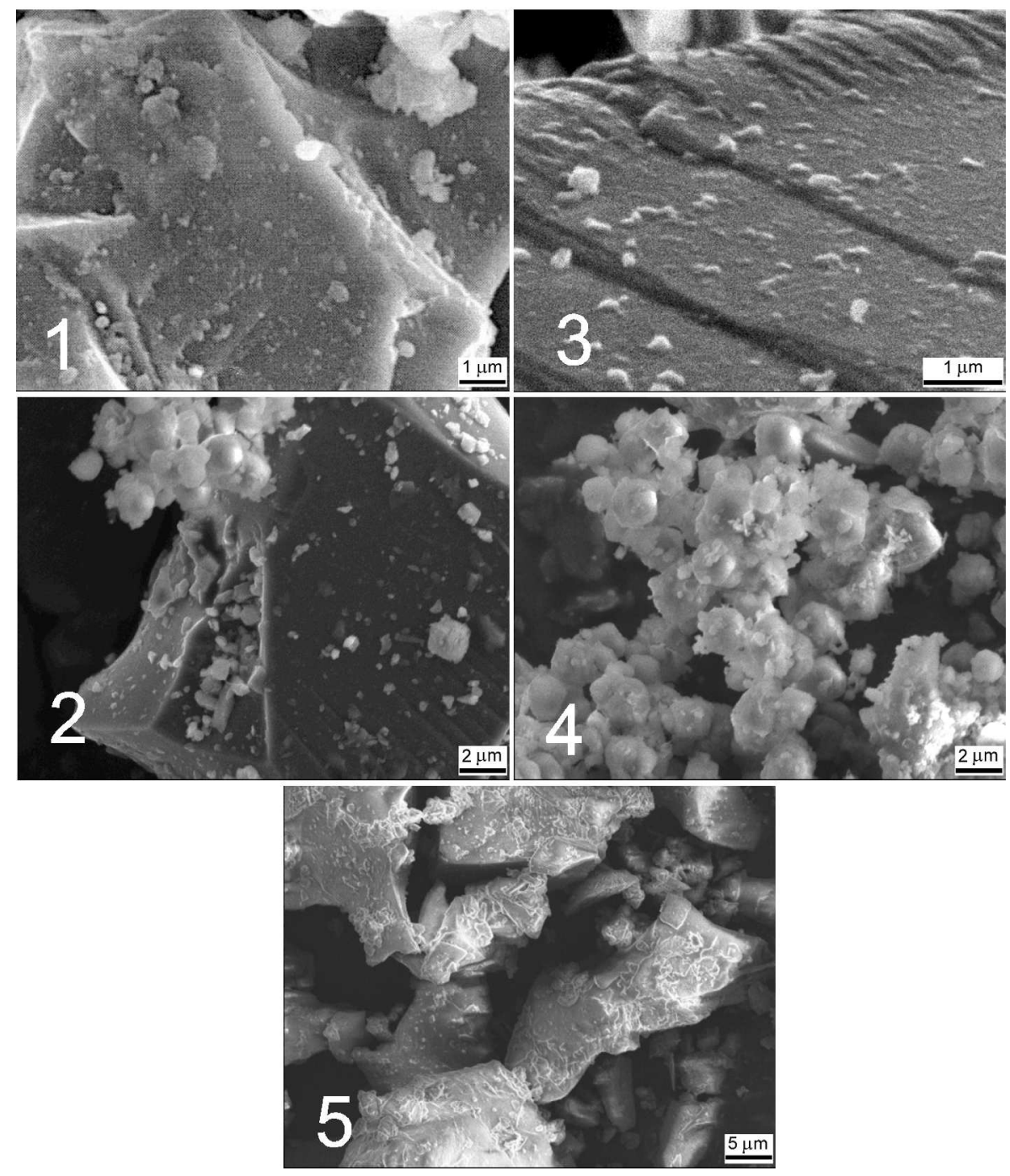

Fig. 2. Surface of GA after exposure to different radiation doses (1) 0; (2) 520 MGy, signs of precipitation of amorphous grains and crystallization; (3) 685 MGy, surface crystallization; (4) 685 MGy, aggregation of amorphous phase; (5) 1409 MGy, formation of microcrystals.

Figure 2 presents the SEM results for GA irradiated with different doses. In a set of images (Fig. 2) modification of the surface of irradiated grains of additive was observed, indicating possible phase transformation induced by energy absorption. Individual images show: the initial state of grain surface (Fig. 2 (1)), appearing of grains of an amorphous phase and evidences for crystallization at 510 MGy (Fig. $2(2)$ ). The following images show: distinct signs of crystallization at 685 


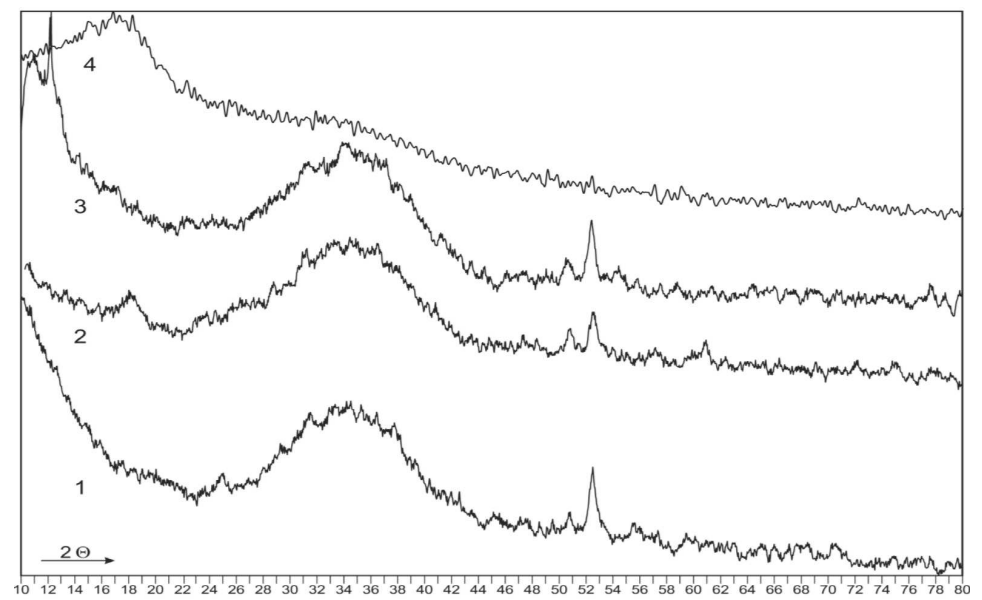

Fig. 3. XRD diagrams for GA additive irradiated with the following gamma doses [MGy]: (1) 0, (2) 68, (3) 520, (4) 1409.

MGy (Fig. 2 (3)), aggregation of an amorphous phase at 685 MGy (Fig. 2 (4)), formation of fine crystallites on the surface of aggregates of amorphous grains at 1409 MGy (Fig. 2 (5)).

The above mentioned changes was not observed when other additives (SF, FA) were used, i.e. additives for which the energy of radiation is not converted into chemical energy.

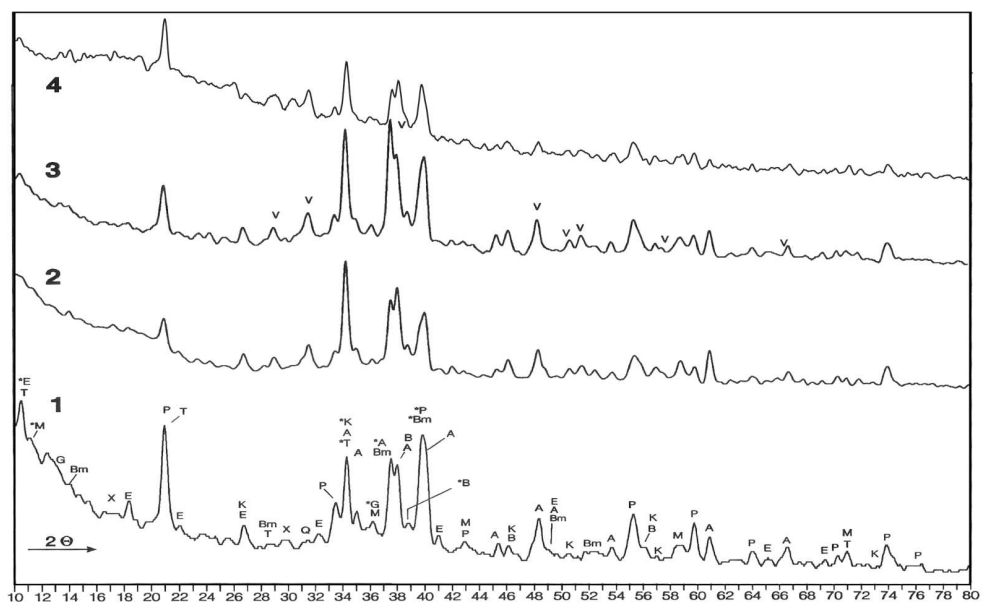

Fig. 4. Set of XRD diagrams obtained for pure cement paste ( $\left.\mathrm{PO}_{\mathrm{OPC}}\right)$ after exposure to the following radiation doses [MGy]: (1) 0, (2) 130, (3) 290, (4) 836.

Figure 4 presents the XRD results for pure cement paste $\mathrm{PO}_{\mathrm{CEMI}}$ irradiated with different doses. Figure 4 (1-4) illustrates a drop of fraction of crystalline 


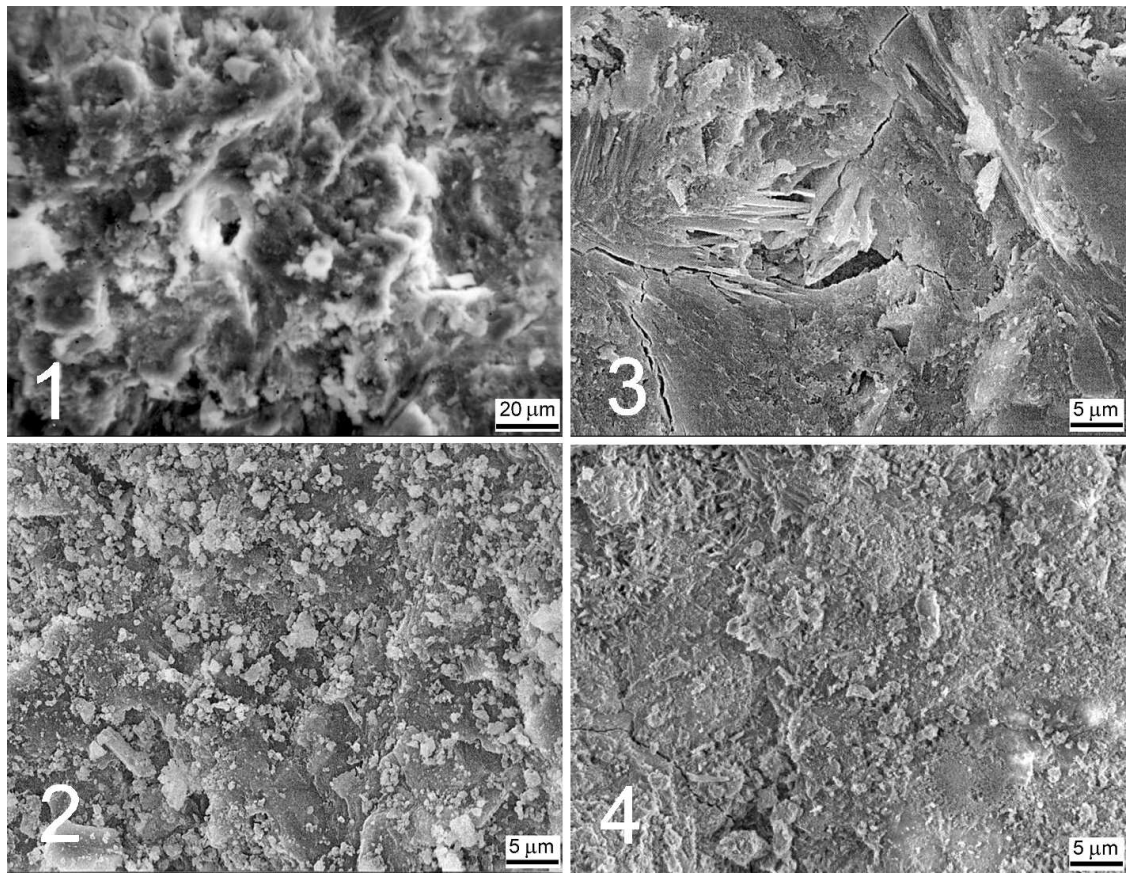

Fig. 5. Irradiated cement paste without an additive (POOPC) observed in SEM: (1) 0 MGy, (2) 130 MGy, (3) 290 MGy, (4) 836 MGy - sample destruction.

phases formed during cement hydratation. Moreover, decomposition of cement clinker phases was observed (alite, belite, brownmillerite).

SEM observations (Fig. 5) indicate that pure cement paste has the lowest resistance to gamma radiation. Pseudomorphoses ${ }^{\text {I }}$ were already observed after a dose of 130 MGy.

It can be deduced from Fig. 6 (presenting the XRD results for cement paste containing the GA additive - PGA30) that fraction of crystalline phase formed previously during cement hydratation has been reduced with increased radiation dose. GA additive stabilizes the content of $\mathrm{Ca}(\mathrm{OH})_{2}$, at the maximum radiation dose a new crystalline phase (quartz) appeared (Fig. 7 (5)). Decomposition of three clinker relict phases, above mentioned, was also observed.

It was concluded from SEM observations of cement paste containing GA additive (Fig. $7(3)$ ) that appearing of pseudomorphoses was deplaced toward larger radiation doses. The same observation concerns decomposition of clinker relict phases (alite, belite, brownmillerite).

Figure 8 presents the results of XRD for a paste that contains the silica fume (PSF10). It is evident from that figure that decomposition of crystalline

\footnotetext{
IThe original hydrated minerals of the cement matrix vanished due to their gamma-induced decomposition. Remaining caves with shape of the original material was filled in with the residual substances.
} 


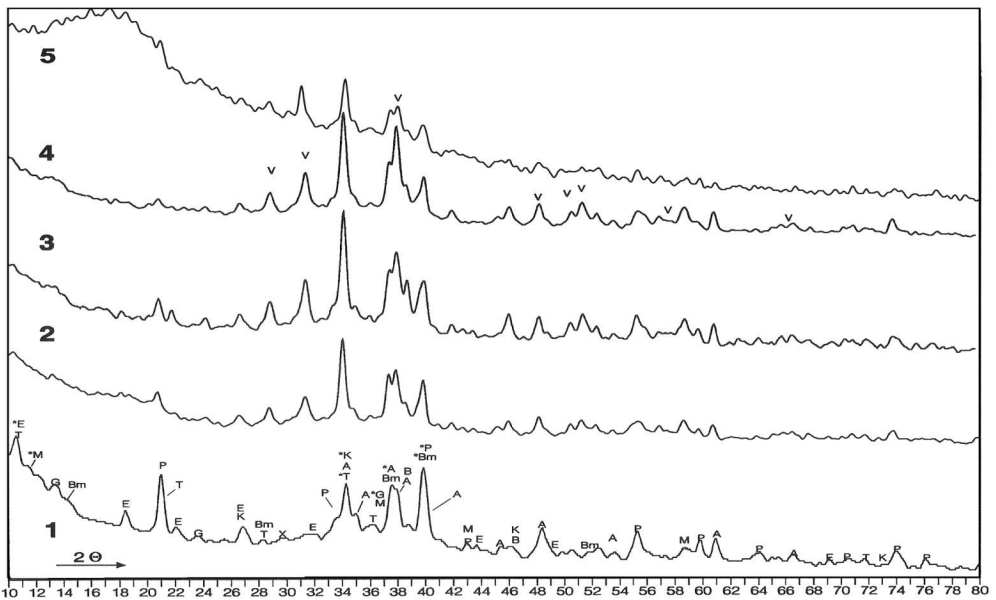

Fig. 6. XRD diagrams of PGA30 cement paste after exposure to the following radiation doses [MGy]: (1) 0, (2) 130, (3) 290, (4) 466, (5) 1188.

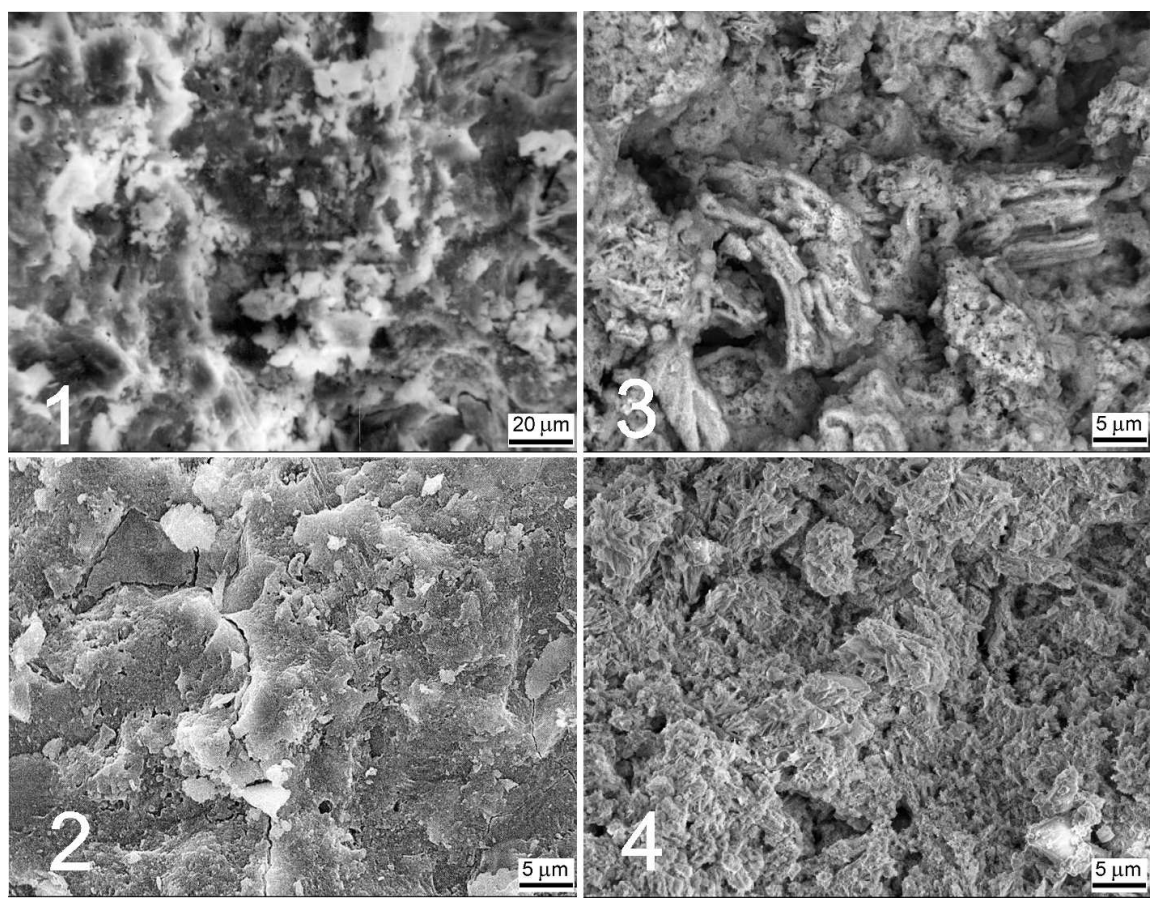

Fig. 7. SEM images of cement paste containing GA additive (PGA30) after exposure to the following radiation doses [MGy]: (1) 0, (2) 290, (3) 466, (4) 1188.

phases (a result of cement hydratation and pozzolana reactions), progressed with increasing radiation dose, leading to amorphization (Fig. 8 (4)). Decomposition of clinker phases was also observed. Figure 9 presents the results of SEM for 


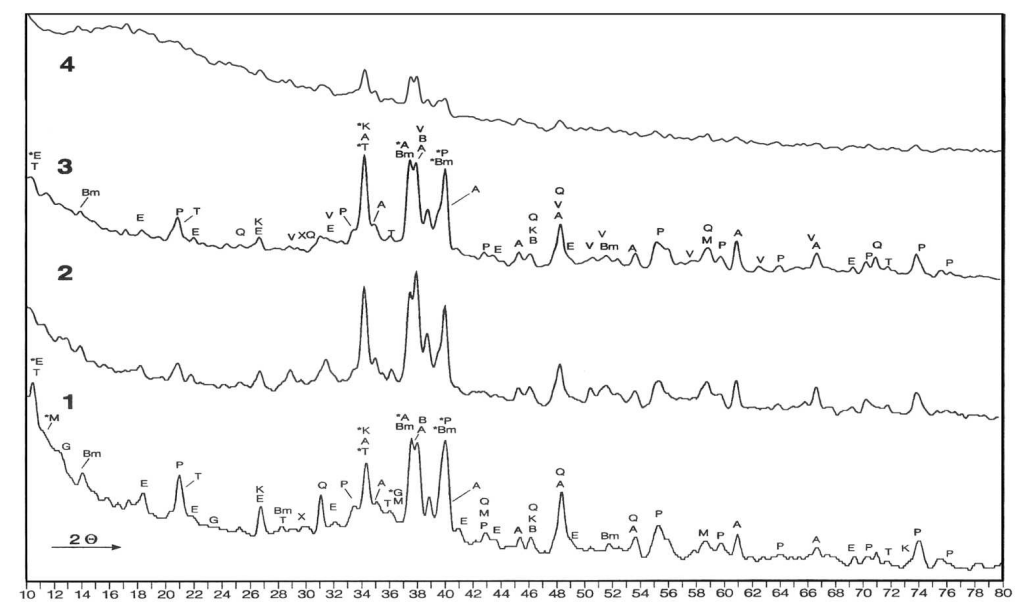

Fig. 8. XRD diagrams of cement paste containing silica fume (PSF10) after exposure to the following radiation doses [MGy]: (1) 0, (2) 290, (3) 466, (4) 1188.
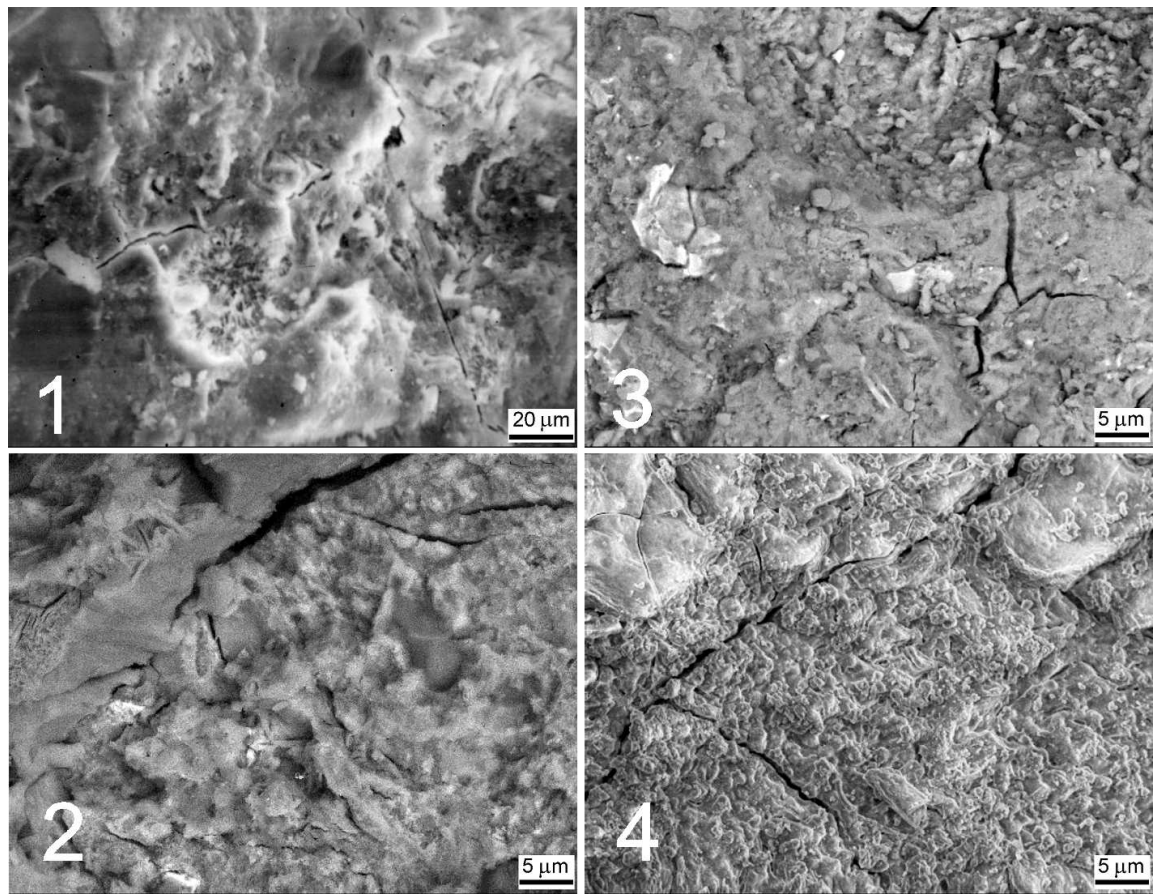

Fig. 9. SEM images of cement paste containing silica fume (PSF10) after exposure to the following radiation doses [MGy]: (1) 0, (2) 290, (3) 466, (4) 1188.

paste containing silica fume (PSF10). Pseudomorphoses were observed at a dose of 290 MGy (Fig. 9 (2)). Progressively with radiation dose microcracks appeared (Fig. 9 (3)). In Fig. 9 (4) the completely amorphous cement matrix is shown. 


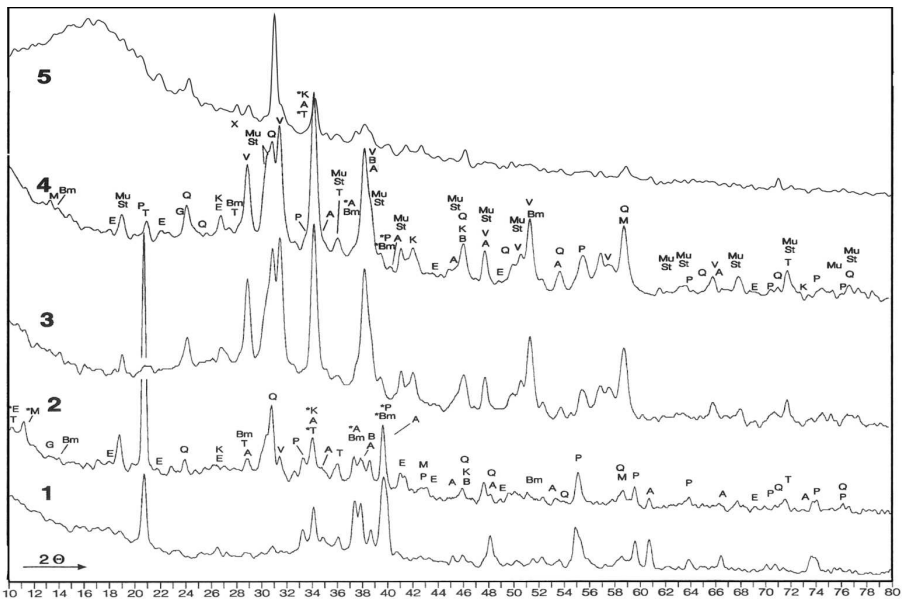

Fig. 10. XRD diagrams of cement paste: (1) without an additive, $\mathrm{PO}_{\mathrm{OPC}}-0$ [MGy]; and paste containing fly ash (PFA60) after the following radiation doses [MGy]: (2) 0, (3) 290, (4) 466, (5) 1188.

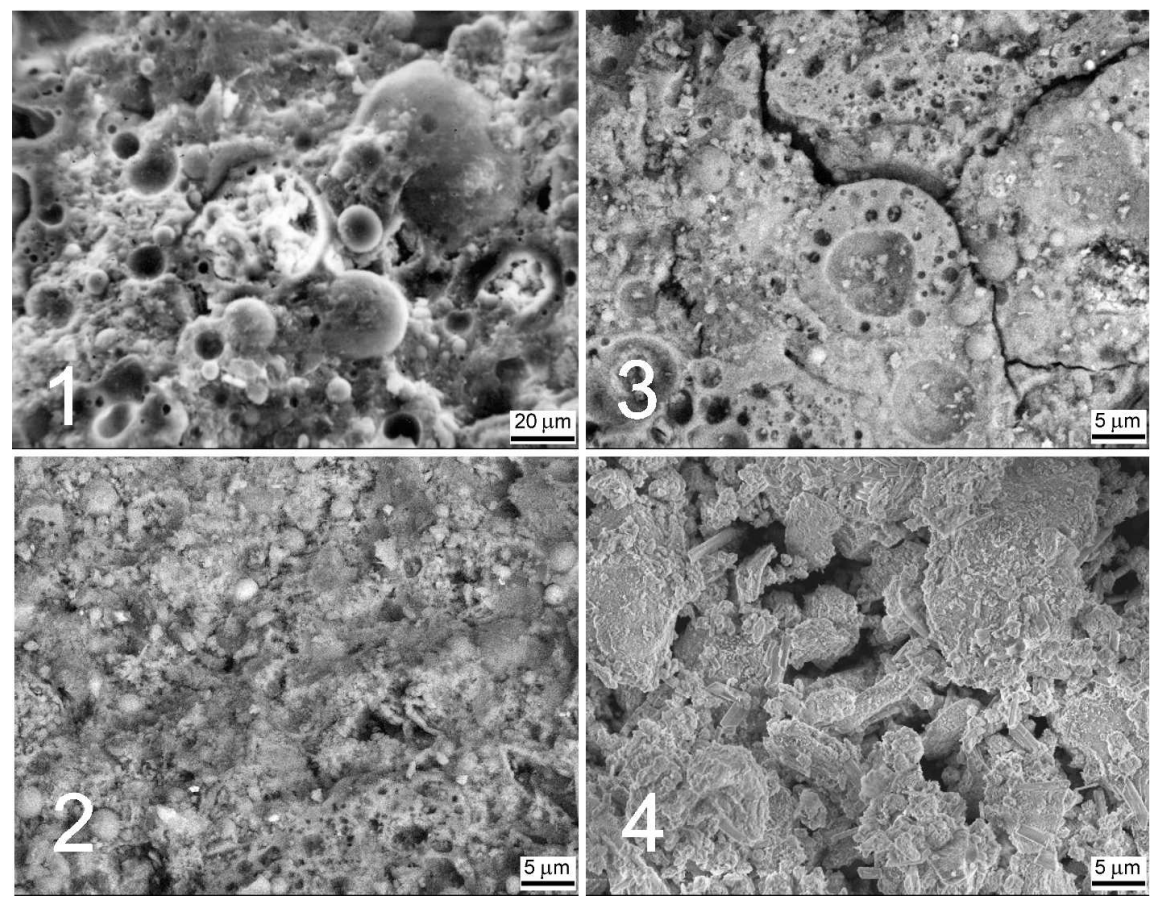

Fig. 11. SEM images of cement paste containing fly ash (PFA60) after exposure to the following radiation doses [MGy]: (1) 0, (2) 290, (3) 466, (4) 1188.

Figure 10 presents the results of XRD for paste containing fly ash (PFA60). It is evident that with inreasing gamma radiation dose, the fraction of crystalline 
phases dropped. Amorphization of cement hydrates under influence of gamma radiation has revealed crystalline phases, which have existed in the cement paste at zero radiation dose, and had been introduced with ash (mullite, syllimanite, quartz) (Fig. 10, curves 3-5). Decomposition of clinker phases (alite, belite, brownmillerite) was also observed. Figure $6 \mathrm{~b}$ presents the results of SEM for paste containing fly ash (PFA60). Pseudomorphoses have appeared after a radiation dose of 290 MGy (Fig. 11 (2)). Bubbles observed in SEM (Fig. 11 (3)) are the effect of separation of a chemically bonded water. Numerous cracks in cement matrix were also observed. Significant destruction of cement phases is visible in Fig. 11 (4). Phases introduced with fly ash (mainly mullite) are clearly visible.

Changes in cement matrix with different additives exposed to gamma radiation are summarized in Fig. 12.

On the basis of the performed observations the cement matrix decomposition process could be discussed.

Figures 5, 7, 9, 11 suggest that the effect of the gamma radiation on the cement paste increases more pronouncedly with the radiation dose. This finding is confirmed by XRD results shown in Figs. 4, 6, 8, 10. PO $\mathrm{OPC}_{\text {cement paste }}$ without additives (Figs. 4, 5) and PSF10 paste containing silica fume (Figs. 8, 9) had the lowest resistance to gamma radiation. PFA60 cement paste containing fly ash revealed higher resistance to gamma radiation, however at a large dose of irradiation a decomposition of the cement matrix was observed (Figs. 10, 11).

(a)

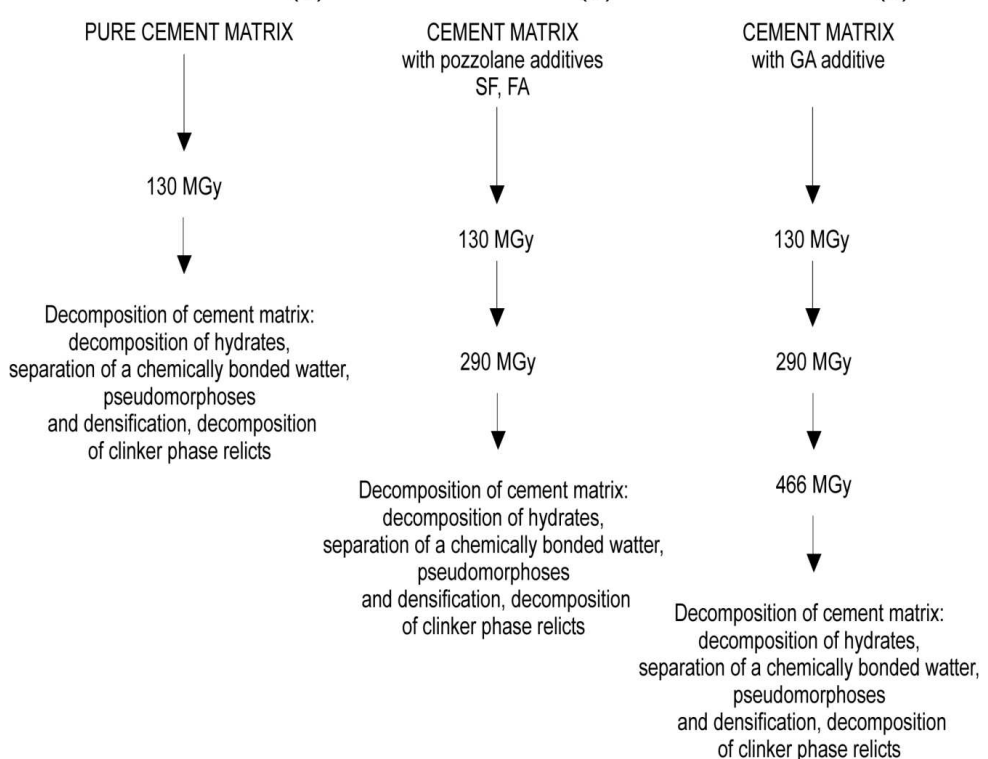

Fig. 12. Effect of the additives on the cement matrix durability. 
Radiation induced amorphization of cement hydrates in a paste containing PFA60 ash, and finally the decomposition of the cement phases revealed the presence of the most resistant crystalline phases (mullite, syllimanite and quartz) introduced with the ash (Fig. 10). Bubbles observed in SEM are the effect of separation of a chemically bonded water (Fig. 11).

SEM observations revealed the following steps of the destruction process: decomposition of hydrates, separation of a chemically bonded water, appearance of pseudomorphoses and densification. In the irradiated cement paste with GA additive the above-mentioned sequence of the phenomena occurs at higher radiation doses to produce the level of damage similar to the observed for the other pastes (Fig. 4). Comparison of the XRD data for basic cement paste with those for the cement pastes containing GA, SF and FA additives (Figs. 4, 6, 8, 10) indicates that, when omitting influence of preferred orientation on the peak intensity, the radiation applied in this study has induced decomposition of both hydrates and clinker phase relicts, but at different doses. In GA containing cement paste the decomposition of relicts and hydrates occurred upon irradiation with larger doses (Fig. 12c).

The results obtained in this study indicate that the GA additive has increased in the durability of cement composites. The SEM and XRD results presented were obtained in a part of complex studies of the cement-matrix resistance to various corrosive factors.

The highest applied radiation dose was about $40 \%$ above than anyone reported in literature in studies of the long term performance of concrete in nuclear applications [17], furthermore for the first time the influence of temperature was eliminated.

Further research is planned using synchrotron radiation in order to better describe structural transformations leading to increased durability of the cement-matrix protective effect against gamma radiation.

\section{References}

[1] K.E. Sickafus, R.W. Grimes, J.A. Valdez, A. Cleave, M. Tang, M. Ishimaru, S.M. Corish, C.R. Stanek, B.P. Uberuaga, Nature Mater. 6, 217 (2007).

[2] J. Alper, Science 280, 826 (1998).

[3] R. Stone, Science 294, 422 (2001).

[4] F. Gibb, P. Attril, Geology 31, 657 (2003).

[5] V.G. Papadakis, M.N. Fardis, C.G. Vayenas, ACI Mater. J. 89, 119 (1992).

[6] H.F.W. Taylor, Cement Chemistry, 2nd ed. Thomas Telford, 1997.

[7] J.A. Janik, W. Kurdowski, R. Podsiadły, J. Samseth, Acta Phys. Pol. A 100, 529 (2001).

[8] J. Janotka, L. Bagel, in: Role of Concrete in Nuclear Facilities, Thomas Telford Publ., London 2005, p. 51.

[9] A. Eowińska-Kluge, Patent 382489, Pending 2007. 
[10] A. Łowińska, K. Tomkowiak, J. Wożniczek, Patent 12 6268, Patent Office, Poland 1983.

[11] A. Łowińska-Kluge, Patent 166057, Patent Office Poland 1993.

[12] A. Łowińska-Kluge, Con. Chem. Conference, ConChem, Dusseldorf 1997, p. 19.

[13] H. Marciniak, Xdata - Background Tracer for X-Ray Diffractometr Data Storage, Warszawa 1992.

[14] H. Marciniak, Xview - Graphics Program for View and Transform of X-Rray Diffraction Data, Warszawa 1994.

[15] H. Marciniak, R. Diduszko, Xrayan - X-Ray Phase Analysis, Warszawa 1994.

[16] W. Kraus, G. Nolze, PowderCell, BAM, Berlin 1999.

[17] D.L. Fillmore, P.L. Winston, S.L. Morton, C.R. Hoffman, L.A. Van Ausdeln, T. Saegusa, K. Shirai, T. Hattori, A. Sasahara, Am. Soc. Mech. Eng., Pressure Vessels Piping Div. 7, 639 (2005). 